\title{
Advancing Science through Diversity Begins with Cultural Immersion in Science Education
}

\author{
Darshana T. Shah, PhD'
}

Author affiliations are listed at the end of this article.

Correspondence to: Darshana T. Shah, PhD Marshall University Joan C. Edwards School of Medicine shah@marshall.edu

\section{KEYWORDS}

Science Education, Diversity

Age, culture, gender, race, religion, sexual orientation, social upbringing, physical challenges, work experience, scientific discipline, ethnicity, and nationality. This list continues to grow as we more seriously recognize and respect diversity in the workplace.

"Science Benefits from Diversity," an editorial published in Nature, ${ }^{1}$ suggests that building a sustainable future for research that truly represents society is vital to encouraging participation in science from as many sectors of the population as possible. Greater diversity allows scientific organizations to derive an "innovation dividend" that leads to smarter, more creative teams, hence opening the door to discoveries ${ }^{2}$. When science lacks diversity, science suffers. When science suffers, it becomes everyone's problem.

Despite the benefits, broadening diversity and embracing ways of seeing things has proven a difficult path for scientific organizations. Institutions and departments develop procedures to ensure they can draw from a broader pool of talent; however, the lack of culturally sensitive materials available in science education often unfairly measure and fail to accurately represent the strengths of candidates from diverse backgrounds. Because of this, these candidates might be less likely to find themselves "outstanding " or "excellent" and may not even apply to jobs in the science field. An editorial in this volume of MJM on "On Watson, Racism, and Standardized Tests" underscores why current standardized methods of measuring an individual's potential are flawed and hopes that we, as a society, will rise above judging students by scores on tests that are inherently cuturally biased.

Efforts are being made to increase diversity in science by building pipeline programs to reach out to underrepresented communities who may not otherwise consider science as a career option; however, such programs have not produced the needed outcome of increasing diversity in science and health professional schools. Additionally, building such programs has proven challenging as science education has been devoid of cultural inclusion. Science is delivered in "culture-free fashion" because many science 
educators believe "science is pure" and thus escapes the influence of equity pedagogies, trends, or culture. Because of this delivery, many students cannot or do not process scientific information, and may internalize the notion that they cannot do science or are not expected to process scientific information.

Culturally inclusive science integrates the learner's culture into the academic and social context of the science classroom to aid and support science learning. ${ }^{3}$ What is sought and needed in science education is science curricula models that integrate the education of traditional science with cultures within the classroom and a diverse science educator workforce with the knowledge to equip students for success.

Building pipeline programs is important for recruitment, but retention is equally essential. Mentoring is vital for all young health professionals and scientists, especially for those who have been marginalized by academic culture. Diversity efforts should not stop when applicants are through the door. Rigorous action to effect change on recruitment and retention can and does make a difference. $A$ greater effort toward diversifying science in all forums is overdue.

\section{AUTHOR AFFILIATIONS}

1. Marshall University Joan C. Edwards School of Medicine

\section{REFERENCES}

1. Science benefits from diversity. Nature. 2018;558(7708).

2. Gender diversity leads to better science. PNAS. 2017; 114(8):1740-1742.

3. Equity pedagogy: an essential component of multicultural education. Theory into Practice. 1995;34(3):152-158. 